\title{
Growth and Nutrition in Children with Trichothiodystrophy
}

\author{
Emily C. Atkinson, BA ${ }^{1}$, Diana Thiara, BA ${ }^{1}$, Deborah Tamura, RN, MS $^{2}$, John J. DiGiovanna, \\ $M^{2}$, Kenneth H. Kraemer, MD², and Colleen Hadigan, MD, MPH ${ }^{1}$ \\ ${ }^{1}$ Laboratory of Immunoregulation, National Institute of Allergy and Infectious Diseases, National \\ Institutes of Health, Bethesda, MD \\ 2DNA Repair Section, Dermatology Branch, Center for Cancer Research, National Cancer \\ Institute, National Institutes of Health, Bethesda, MD
}

\section{Abstract}

Objective-Trichothiodystrophy (TTD) is a rare autosomal recessive disorder of DNA repair and transcription. Patients have multisystem abnormalities including alterations in growth and development. This report characterizes the growth and nutritional status of a cohort of children with TTD.

Study Design-Twenty-five patients with TTD were evaluated through a natural history study of patients with DNA repair diseases at the National Institutes of Health. Mean length of followup was 2.7 years. Retrospective and prospective data on nutritional status and height/weight were collected.

Results-In general, patients with TTD had considerable abnormalities in growth, with a mean height-for-age $\mathrm{z}$-score of -2.75 and a mean weight-for-age $\mathrm{z}$-score of -2.60 at baseline clinical evaluation. However, the median weight-for-length at baseline was $50^{\text {th }}$ percentile and indicators of adequate nutrition such as serum albumin, hemoglobin, and vitamins D and B12 were largely within normal limits. Changes in growth parameters as children aged were characterized by further separation from standard growth curves [change height-for-age z-score/year $(-0.18 \pm 0.42)$ and weight-for-age $\mathrm{z}$-score/year $(-0.36 \pm 0.51)]$. Patients who died during follow-up $(n=5)$ had significantly lower standardized height $(\mathrm{p}=0.03)$ and weight $(\mathrm{p}=0.006)$, weight-for-length $(<0.0001)$ and higher heart rates $(\mathrm{p}=0.02)$ compared to the remainder of the cohort.

Conclusion-Children with TTD have markedly diminished weight-for-age and height-for-age relative to reference populations. The cause for this stunted growth remains unclear but does not appear to be related to poor nutrient absorption or malnutrition.

\section{Keywords}

Trichothiodystrophy; failure to thrive; growth; nutrition; DNA repair defects; transcription defects

Address correspondence to: Colleen Hadigan, MD, MPH, 10 Center Drive, Bldg 10, Rm 11C103, Bethesda, MD 20892, hadiganc@niaid.nih.gov, 301-594-5754, Fax 301-402-4097.

Financial Disclosure: The authors have no financial relationships to disclose relevant to this article.

Conflict of Interest: The authors have no conflicts of interest to disclose.

Clinical Trial Registration: Examination of Clinical and Laboratory Abnormalities in Patients with Defective DNA Repair: Xeroderma Pigmentosum, Cockayne Syndrome, or Trichothiodystrophy (NCT00001813). 


\section{Introduction}

Trichothiodystrophy (TTD) is a rare autosomal recessive disorder of DNA repair and transcription characterized by multisystem defects including short, dry, brittle hair, ichthyosis of the skin, and thin, peeling, slow-growing nails.(1) Affected patients' hair exhibits multiple shaft abnormalities and a particular pattern of alternating light and dark bands when viewed under polarized microscopy. This banding pattern is termed "tiger-tail banding" and is diagnostic for the condition.(2) Additional features of TTD are quite variable and can range from mild intellectual delay with short brittle hair to severe developmental delay, dysmyelination and life-threatening, recurrent infections.(3) Approximately half of TTD patients demonstrate an exaggerated response to ultraviolet radiation, resulting in severe sunburns after minimal exposure.(4) While intrauterine growth restriction is infrequent (8\%), more than one-third of infants born with TTD are small for gestational age.(5) Short stature, along with failure to thrive, was reported in up to $73 \%$ of cases and TTD was associated with a 20 -fold increased incidence of death before age 10 years.(6) A literature review identified approximately 100 cases of TTD worldwide, with an estimated incidence of 1 in 1 million live births. $(6,7)$

There are four genes most commonly found to be defective in TTD. Three of these genes $E R C C 3(X P B), E R C C 2(X P D)$, and GTF2H5(TTDA), are subunits of the transcription factor $\mathrm{IIH}$, which is necessary for nucleotide excision and transcription repair.(8-10) A fourth gene, Corf11(TTDN1), has a still-unidentified function.(11)

Short stature is a characteristic feature of TTD. The growth pattern of most patients with TTD appears to be markedly abnormal while a few patients follow a relatively normal pattern of height and weight acquisition. The purpose of this report is to evaluate the growth characteristics and nutritional status of a cohort of 25 patients with TTD and to identify potential clinical or laboratory correlates with growth failure in this population.

\section{Materials and Methods}

\section{Study participants}

Twenty-five subjects meeting the clinical criteria for TTD were evaluated at the National Institutes of Health (NIH) between 2001 and 2012 as part of a prospective natural history study of DNA repair diseases. While followed on study, patients received extensive medical and laboratory evaluation in an effort to better characterize the genetic, phenotypic, and clinical features of the condition. The research was approved by the National Cancer Institute's Institutional Review Board, and informed consent was obtained from all study participants. In order to assess subjects' growth and nutrition, we prospectively collected data on height, weight and laboratory indices of nutritional status and conducted retrospective chart reviews. Additionally, we reviewed outside medical records from referring physicians and collected data including weight, length, and height measurements and documented growth curves. Data for growth parameters used for analysis included first evaluable measurements (from chart review or prospective measurement), as well as all time points following entry into the cohort, up to the last NIH encounter. 
The following variables were extracted from NIH medical records: heart rate, blood pressure, bone age, date of feeding tube placement, mid-parental height, mid-parental weight, albumin, hemoglobin, mean corpuscular volume (MCV), hemoglobin A2 (HgbA2), cholesterol, 25-hydroxyvitamin D, vitamin B12, serum iron, transferrin, transferrin percent saturation, thyroid stimulating hormone, folate, and fecal fat. Resting energy expenditure (REE) was measured in two subjects using 30 minutes of indirect calorimetry following an overnight fast.

\section{Statistical analyses}

Height-for-age and weight-for-age z-scores were calculated using the EMMES Corporation's Standardized Height and Weight Calculator.(12) Weight-for-length (up to 36 months) and weight-for-stature (> 36 months) were estimated at time points with measured length (stature) and weight using the CDC standardized growth charts. Body mass index (BMI) was also calculated $\left(\mathrm{kg} / \mathrm{m}^{2}\right)$ and CDC standardized growth data used for BMI zscores. In addition, for subjects with more than one set of evaluable measurements, change in weight-forage and height-for-age z-scores per year was calculated using the first and last evaluable measurements divided by the number of years of follow-up. All statistical analyses were conducted using SAS JMP version 8.0 (SAS Institute, Cary, NC). P-values were two-sided and p-values of $<0.05$ were considered to be statistically significant.

\section{Results}

Ten subjects were female and fifteen were male (Table 1). Patients were seen between one and six times, with the longest follow-up at nine years. The mean length of prospective follow-up was 2.7 years. Height and weight data were available for an average period of 4.6 \pm 2.9 years. The mean age at first NIH visit was $3.8 \pm 2.5$ years and the mean age at last follow-up was $6.4 \pm 3.8$ years ranging from 1 to 15 years of age. Most of these children (92\%) were Caucasian, one was Asian (4\%), one was African-American (4\%) and two patients $(8 \%)$ self-identified as Hispanic. Five of the twenty-five patients (20\%) died since study initiation.

The average age for the first evaluable length or weight was $1.9 \pm 2.3$ years (range 0 to 7 years). The mean height-for-age $\mathrm{z}$-score at the first evaluation and last follow-up were -2.75 \pm 2.09 and $-2.90 \pm 2.45$, respectively (Table 2 ). The mean weight-for-age $\mathrm{z}$-scores were $-2.60 \pm 2.35$ at first measured time point and $-3.24 \pm 3.29$ at last follow-up. The mean BMI was $15.0 \pm 3.3 \mathrm{~kg} / \mathrm{m}^{2}$ and the median weight-for-length was $50^{\text {th }}$ percentile at first evaluable time point. The degree of stunting was proportional with regard to weight and height for approximately half of the subjects; $52 \%$ of participants had a weight-for-length at the $25^{\text {th }} \%$ ile or greater at all evaluable time points. Changes in growth parameters were characterized by a decrease in height-for-age z-score per year $(-0.18 \pm 0.42)$, as well as a decrease in weight-for-age $z$-score per year $(-0.36 \pm 0.51)$ as children aged (Figure 1$)$.

At first NIH visit, 4 of 25 patients (16\%) had low serum albumin (none below $3.2 \mathrm{~g} / \mathrm{dL}$ ) (Table 2). No patients were found to have low levels of vitamin B12, and only one patient had a folate level below the normal range. Additionally, only one patient had low serum iron. In general, anemia was not present; however, one patient had a hemoglobin level of 11 
$\mathrm{g} / \mathrm{dL}$, which was below the normal range. Low mean corpuscular volume (MCV) was common though, with $46 \%$ of subjects below the lower limit of the normal range for their age (MCV observed range in the cohort was $61-88 \mathrm{fL}$, the group mean MCV was $74 \mathrm{fl}$ ). Of the 19 patients who had hemoglobin electrophoresis at their baseline visit, the mean HgbA2 was $4.2 \pm 1.2 \%$ (normal range $2.2-3.2 \%$ ), with $79 \%$ of patients falling outside the normal range. Low MCV values were associated with increased $\operatorname{HgbA2}(n=19 ; \mathrm{r}=-0.825$; $\mathrm{p}<0.0001$ ). Two subjects had mildly elevated TSH, but it was not thought to be clinically significant as their T4 levels were within normal limits.

Seventeen of twenty-five patients were found to have mutations in the ERCC2(XPD) gene. The patients with $E R C C 2(X P D)$ mutations had weight-for-age z-scores that were significantly lower than the other TTD patients both at baseline ( $-3.53 \pm 2.12$ vs. $-0.68 \pm$ 1.54; $\mathrm{p}=0.002)$ and averaged over the length of follow-up ( $-3.80 \pm 2.81$ vs. $-0.65 \pm 1.39$; $\mathrm{p}=0.001$ ). In addition, weight-for-length percentile was significantly lower at baseline $(27 \pm$ $23 \%$ ile in XPD vs. $79 \pm 19 \%$ ile in non-XPD, $\mathrm{p}<0.0001)$ and at last follow-up $(15 \pm 14 \%$ ile vs. $65 \pm 33 \%$ ile, $\mathrm{p}=0.003)$ in patients with $E R C C 2(X P D)$ mutations. The mean height-forage z-score over the length of follow-up was significantly decreased in the XP-D cohort $(-3.35 \pm 1.84$ vs. $-1.61 \pm 2.36 ; \mathrm{p}=0.03)$, whereas the baseline height-for-age $\mathrm{z}$-score did not differ between XPD patients and the rest of the cohort ( $-3.07 \pm 1.81$ vs. $-1.83 \pm 2.70$; $\mathrm{p}=0.12)$. At last evaluation, heart rate was significantly higher $(127 \pm 16 \mathrm{bpm}$ vs. $106 \pm 13$ bpm, $\mathrm{p}=0.004)$ and BMI was significantly lower ( $14.3 \pm 1.3$ vs. $18.7 \pm 4.3$, $\mathrm{p}=0.02)$ among those in the cohort with XPD mutations compared to others in the cohort.

The parental heights and weights for the 16 mothers and 16 fathers with available data fell within the reported normal ranges for adult men and women in the United States. The mean maternal height and weight were $165 \pm 6 \mathrm{~cm}$ and $67 \pm 15 \mathrm{~kg}$, respectively. The mean paternal height and weight were $176 \pm 5 \mathrm{~cm}$ and $94 \pm 22 \mathrm{~kg}$, respectively. The mean heart rate first measured for subjects was $120 \pm 19$ beats per minute $(n=24$, mean age at measurement $4.6 \pm$ 2.8 years, normal range for children age $4-5$ y is $65-135 \mathrm{bpm}$ ).(13) At last follow-up, there was a significant negative correlation between heart rate and height-for-age $\mathrm{z}$-score $(\mathrm{n}=20$, $\mathrm{r}=-0.654, \mathrm{p}=0.002)$ as well as heart rate and weight-for-age $\mathrm{z}$-score $(\mathrm{n}=22, \mathrm{r}=-0.642$, $\mathrm{p}=0.001$ ). In other words, patients with faster heart rates were more likely to be stunted and/or underweight for their age.

Two of the patients had REE measured during their visits to the NIH. Ten-year-old patient TTD355BE with a resting heart rate of $136 \mathrm{bpm}$ was found to have a REE of $907 \mathrm{kcal} / \mathrm{day}$, which is similar to the value of $934 \mathrm{kcal} / \mathrm{day}$ predicted by the Schofield-HW formula. In addition, his respiratory quotient (RQ) of 0.83 was in the normal range (0.7-1.0). Twelveyear-old patient TTD404BE with a resting heart rate of $117 \mathrm{bpm}$ was found to have a normal REE of $1242 \mathrm{kcal} /$ day (as compared to the Schofield-HW value of $1170 \mathrm{kcal} / \mathrm{day}$ ) and normal RQ (0.93).

Bone age data were available for twenty-one patients. At the time of the bone age determination, the mean chronological age of the cohort was 4.6 years and the mean bone age of the cohort was 4.4 years (mean difference $0.2 \pm 1.1$ years, $\mathrm{p}=0.4$ ). Two subjects had delayed bone ages that differed by more than two years from their chronological age ( 2.6 
and 3.1 years younger respectively), representing potential for improved linear growth. Growth hormone (GH) and IGF-1 were not measured as part of this study; one subject (TTD412BE) reportedly received GH treatment for short stature for 15 months between the ages of 4 and 5 years, during which time his height and weight both remained well below

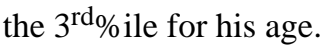

Fecal fat was measured for three patients, and was found to be within normal limits. To assess fat soluble vitamin levels we measured $25-\mathrm{OH}$ vitamin D. No subject met the criteria for vitamin D deficiency defined as $25 \mathrm{OH}$ vitamin $\mathrm{D}<10 \mathrm{ng} / \mathrm{mL}$, but four subjects had vitamin D levels $<25 \mathrm{ng} / \mathrm{mL}$. This may be related to the sun protection used by TTD patients because of their marked skin sun sensitivity. Four patients in the cohort had received gastric feeding tubes (G-tubes) at some point after birth. One subject had a G-tube placed before enrollment and kept it throughout follow-up, and one subject's G-tube was placed at birth but removed before enrollment. Both patients who had G-tubes placed while on study (TTD412BE and TTD355BE) had low height-for-age z-scores (-2.91 and -3.57) and weight-for-age z-scores (-3.24 and -5.19$)$. Additionally, both of these subjects exhibited minor improvements in weight (change in z-score +0.66 and +0.61 ) with addition of enteral feeding. For the one subject who had height data after tube placement (TTD355BE), z-score height-for-age increased by +0.84 .

Five of the patients died during the study (all with XPD genotype). Patient TTD352BE had a history of asthma and frequent upper respiratory infections. She died at age 9 after developing a viral respiratory infection and MRSA pneumonia. Patient TTD445BE died at age 3 following a prolonged hospitalization. He was admitted for dental surgery to treat multiple caries. Following an uncomplicated surgery, he developed recurrent aspiration pneumonia, respiratory failure and died from complications of pulmonary hypertension and cardiac failure. Patient TTD355BE died at age 12 from acute cardio-pulmonary arrest after administration of a narcotic for severe chronic pain. Patient TTD412BE died at age 9 following a prolonged hospitalization for post-surgical complications following treatment for bilateral osteonecrosis of the hips. He suffered a cardiac arrest during the surgical procedure but was resuscitated. However, he experienced multiple respiratory, cardiac and neurological complications and was removed from ventilator support after severe neurologic compromise was confirmed. Patient TTD351BE lived to age 15, but also died following surgery for bilateral hip dysplasia. Following an uncomplicated surgical procedure, he developed wound infection, was readmitted 2 weeks following the surgery and developed multiple respiratory infections, sepsis and cachexia. He died following a cardio-pulmonary arrest.

Data collected prior to the acute illnesses that led to their death demonstrated that patients who died tended to have lower height-for-age z-scores compared to those who did not die (mean value $-4.54 \pm 2.35$ vs. $-2.36 \pm 1.90$, respectively; $\mathrm{p}=0.03$ ) and lower weight-for-age $\mathrm{z}$-scores compared to surviving patients (mean value $-6.18 \pm 4.05$ vs. $-1.95 \pm 1.72$; $\mathrm{p}=0.006$ ). Baseline weight-for-length (stature) was not significantly different ( $22 \pm 31 \%$ ile vs. $49 \pm 32 \%$ ile, $\mathrm{p}=0.13$ ) between those who died and those who did not die. However, at last follow-up, those who died were all $<3^{\text {rd }} \%$ ile for weight-for-length(stature) and significantly lower than those surviving $(38 \pm 31 \%$ ile, $\mathrm{p}<0.0001)$. Additionally, the patients 
who subsequently died exhibited significantly increased heart rate during study participation compared to the remainder of the cohort (mean value $130 \pm 6 \mathrm{bpm}$ vs. $118 \pm 18 \mathrm{bpm}$; $\mathrm{p}=0.02$ ).

\section{Discussion}

To date, few studies have described the growth of individuals with TTD. In this study, we identified markedly abnormal z-scores for height-for-age and weight-for-age. The WHO Global Database on Child Growth and Malnutrition uses a z-score of $<-2$ to classify low weight-for-age and low height-for-age as moderate to severe malnutrition.(14) Following these guidelines, it might appear that our subjects' growth failure is due to poor nutrition. However, lab indices measured in this subject population do not support a typical pattern of malnutrition. On average, the TTD children had laboratory values in the normal range for several nutritional markers. When measured, fecal fat determinations were in the acceptable range, as were fat soluble vitamin D levels, suggesting intact nutrient absorption.

Furthermore, vitamin and mineral deficiencies were not often identified in our patients. The few REE measurements that were completed indicated that the basal metabolic rate was not elevated over predicted values. Therefore, factors other than absorption or energy expenditure may be impacting growth patterns in this patient population.

One potential mechanism for poor growth in TTD could be mitochondrial dysfunction.(15) It may be that metabolism is disordered in TTD patients, preventing them from building muscle mass, increasing fat stores and growing properly. This was found to be the case in mice with Cockayne syndrome (CS), a similar nucleotide excision repair defect disorder characterized by neurodegeneration and dwarfism in humans.(1) Mice with CS protein deficiency accumulate mitochondrial DNA mutations in subcutaneous fat tissue, leading to increased apoptosis and a consequent loss of subcutaneous fat tissue.(16) In another study, mice with CS were shown to have only $36 \%$ of the amount of abdominal and epididymal fat of wild-type mice, despite consuming about $33 \%$ more food.(17) There was no evidence of malabsorption to explain the decreased fat; however, $\mathrm{O}_{2}$ consumption and $\mathrm{CO}_{2}$ production were elevated in CS mice without increased physical activity. Additionally, genes coding for energy production were seen to be upregulated in CS mice, so the fat loss seen in TTD patients may likewise be due to alterations in regulation of energy production.

The XPD protein is associated with transcription factor IIH which is functionally altered in TTD. Further, mutations in transcription factor IIH have been shown to decrease $\beta$-globin gene expression.(18) Our observation of low MCV in associations with increased HgbA2 in patients with TTD in the absence of clinically significant anemia may be explained in part by effects on transcription factor IIH.

In general, TTD patients' heights and weights tend to drop off the growth curve as they get older, as indicated by a decreasing trend in height-for-age and weight-for-age z-score over time. This is of significance because the TTD patients who died had a greatly diminished height-for-age and weight-for-age z-scores compared to those who survived. Furthermore, their weight-for-length decreased from baseline to last follow-up, indicating a progressive wasting in addition to overall stunting. Our findings are consistent with mouse model studies 
in which TTD mice, who weigh less than wild type mice throughout life, develop progressive cachexia and further weight loss in the weeks preceding their premature death. $(19,20)$ In one study, the difference in weight between XPD-TTD mice and C57BL6 mice could not be explained by differences in food intake. In our cohort, patient deaths were most often due to cardiopulmonary failure following infections or surgical procedures, but it is possible that diminished nutritional reserves further accelerated their overall decline.

Growth hormone (GH) has not been systematically assessed in TTD and was not evaluated in this cohort. The etiology behind patients' stunted growth and failure to thrive remains unclear, and improving growth status proves difficult in this population. The addition of oils to foods to increase caloric density and use of nutritional supplemental beverages may be helpful in optimizing caloric intake in TTD. Although the mechanism for benefit may differ, gastrostomy tube placement is recommended in certain metabolic disorders (21) and has been associated with prolonged survival in spinal muscular atrophy.(22) G-tubes may be beneficial in some cases, as patients in this study appeared to gain height and weight following tube placement, but further data are needed to determine whether this approach should be routinely implemented.

Overall, we have identified dramatically abnormal growth patterns in TTD patients, but the conclusions we draw are limited by the relatively small number of individuals studied. Unfortunately, due to the rarity of the condition, it is difficult to establish a cohort large enough to allow for comprehensive investigation. The length of prospective follow-up was also relatively short, and while the use of retrospective data from growth charts expanded our window of observation, these data may be less accurate than prospectively collected measurement. In addition, direct measurements of fecal fat and REE were limited to only a few subjects. Further analysis of the pathophysiology of the TTD is necessary in order to improve outcomes in this population. In particular, we need to better understand the etiology of height and weight growth failure in order to address it more effectively in the clinical management of these patients. Optimizing growth and nutrition may be key in extending life expectancy in this fragile population.

\section{Acknowledgments}

Funding Source: This research was supported by the Intramural Research Program of the NIH, National Institute of Allergy and Infectious Diseases and the National Cancer Institute, Center for Cancer Research.

\section{References}

1. DiGiovanna JJ, Kraemer KH. Shining a light on xeroderma pigmentosum. J Invest Dermatol. 2012 Mar; 132(3 Pt 2):785-96. [PubMed: 22217736]

2. Liang C, Kraemer KH, Morris A, Schiffmann R, Price VH, Menefee E, et al. Characterization of tiger-tail banding and hair shaft abnormalities in trichothiodystrophy. J Am Acad Dermatol. 2005 Feb; 52(2):224-32. [PubMed: 15692466]

3. Rossi, ACC. Trichothiodystrophy. Orphanet Encyclopedia [Internet]. 2004. Available from: www.orpha.net/data/patho/GB/uk-trichothiodystrophy.pdf

4. Eveno E, Bourre F, Quilliet X, Chevallier-Lagente O, Roza L, Eker AP, et al. Different removal of ultraviolet photoproducts in genetically related xeroderma pigmentosum and trichothiodystrophy diseases. Cancer Res. 1995 Oct 1; 55(19):4325-32. [PubMed: 7671243] 
5. Tamura D, Merideth M, DiGiovanna JJ, Zhou X, Tucker MA, Goldstein AM, et al. High-risk pregnancy and neonatal complications in the DNA repair and transcription disorder trichothiodystrophy: report of 27 affected pregnancies. Prenat Diagn. 2011 Nov; 31(11):1046-53. [PubMed: 21800331]

6. Faghri S, Tamura D, Kraemer KH, Digiovanna JJ. Trichothiodystrophy: a systematic review of 112 published cases characterises a wide spectrum of clinical manifestations. J Med Genet. 2008 Oct; 45(10):609-21. [PubMed: 18603627]

7. Kleijer WJ, Laugel V, Berneburg M, Nardo T, Fawcett H, Gratchev A, et al. Incidence of DNA repair deficiency disorders in western Europe: Xeroderma pigmentosum, Cockayne syndrome and trichothiodystrophy. DNA Repair (Amst). 2008 May 3; 7(5):744-50. [PubMed: 18329345]

8. Hashimoto S, Egly JM. Trichothiodystrophy view from the molecular basis of DNA repair/ transcription factor TFIIH. Hum Mol Genet. 2009 Oct 15; 18(R2):R224-30. [PubMed: 19808800]

9. Itin PH, Sarasin A, Pittelkow MR. Trichothiodystrophy: update on the sulfur-deficient brittle hair syndromes. J Am Acad Dermatol. 2001 Jun; 44(6):891-920. quiz 1-4. [PubMed: 11369901]

10. Savarirayan R, Gardner RJ, Sinclair RD, McDowell M, Cleaver JE. Rough skin, brittle hair, and photosensitivity: a mild phenotypic variant of trichothiodystrophy. J Med Genet. 2000 Apr; 37(4): 312-4. [PubMed: 10819642]

11. Stefanini M, Botta E, Lanzafame M, Orioli D. Trichothiodystrophy: from basic mechanisms to clinical implications. DNA Repair (Amst). 2010 Jan 2; 9(1):2-10. [PubMed: 19931493]

12. Corporation E. Standardized Height and Weight Calculator. [updated 8 Jun 2000; cited 2012 August 30]. Available from: http://www.emmes.com/study/ped/resources/htwtcalc.htm

13. Gunn, VLaN; Christian, editors. The Harriet Lane Handbook: A Manual for Pediatric House Officers. 16. Philadelphia, Pennsylvania: Mosby Inc; 2002.

14. De Onis, MBM. WHO Global Database on Child Growth and Malnutrition 1997. Aug 30. 2012 Available from: http://whqlibdoc.who.int/hq/1997/WHO_NUT_97.4.pdf

15. Jeppesen DK, Bohr VA, Stevnsner T. DNA repair deficiency in neurodegeneration. Prog Neurobiol. 2011 Jul; 94(2):166-200. [PubMed: 21550379]

16. Kamenisch Y, Fousteri M, Knoch J, von Thaler AK, Fehrenbacher B, Kato H, et al. Proteins of nucleotide and base excision repair pathways interact in mitochondria to protect from loss of subcutaneous fat, a hallmark of aging. J Exp Med. 2010 Feb 15; 207(2):379-90. [PubMed: 20100872]

17. Scheibye-Knudsen M, Ramamoorthy M, Sykora P, Maynard S, Lin PC, Minor RK, et al. Cockayne syndrome group B protein prevents the accumulation of damaged mitochondria by promoting mitochondrial autophagy. J Exp Med. 2012 Apr 9; 209(4):855-69. [PubMed: 22473955]

18. Viprakasit V, Gibbons RJ, Broughton BC, Tolmie JL, Brown D, Lunt P, et al. Mutations in the general transcription factor TFIIH result in beta-thalassaemia in individuals with trichothiodystrophy. Hum Mol Genet. 2001 Nov 15; 10(24):2797-802. [PubMed: 11734544]

19. de Boer J, Andressoo JO, de Wit J, Huijmans J, Beems RB, van Steeg H, et al. Premature aging in mice deficient in DNA repair and transcription. Science. 2002 May 17; 296(5571):1276-9. [PubMed: 11950998]

20. Wijnhoven SW, Beems RB, Roodbergen M, van den Berg J, Lohman PH, Diderich K, et al. Accelerated aging pathology in ad libitum fed Xpd(TTD) mice is accompanied by features suggestive of caloric restriction. DNA Repair (Amst). 2005 Nov 21; 4(11):1314-24. [PubMed: 16115803]

21. Sutton VR, Chapman KA, Gropman AL, MacLeod E, Stagni K, Summar ML, et al. Chronic management and health supervision of individuals with propionic acidemia. Molecular genetics and metabolism. 2012 Jan; 105(1):26-33. [PubMed: 21963082]

22. Oskoui M, Levy G, Garland CJ, Gray JM, O’Hagen J, De Vivo DC, et al. The changing natural history of spinal muscular atrophy type 1. Neurology. 2007 Nov 13; 69(20):1931-6. [PubMed: 17998484] 

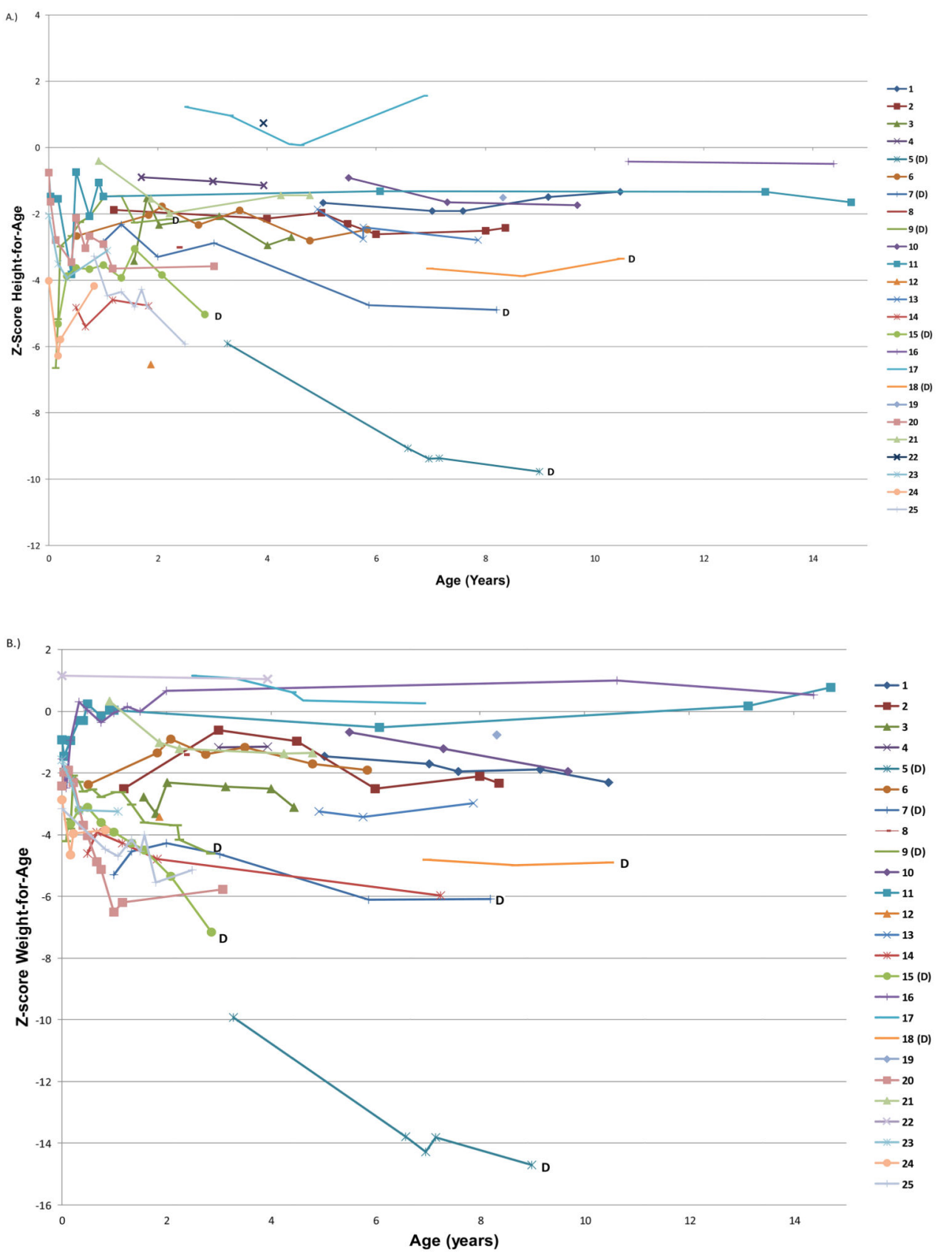


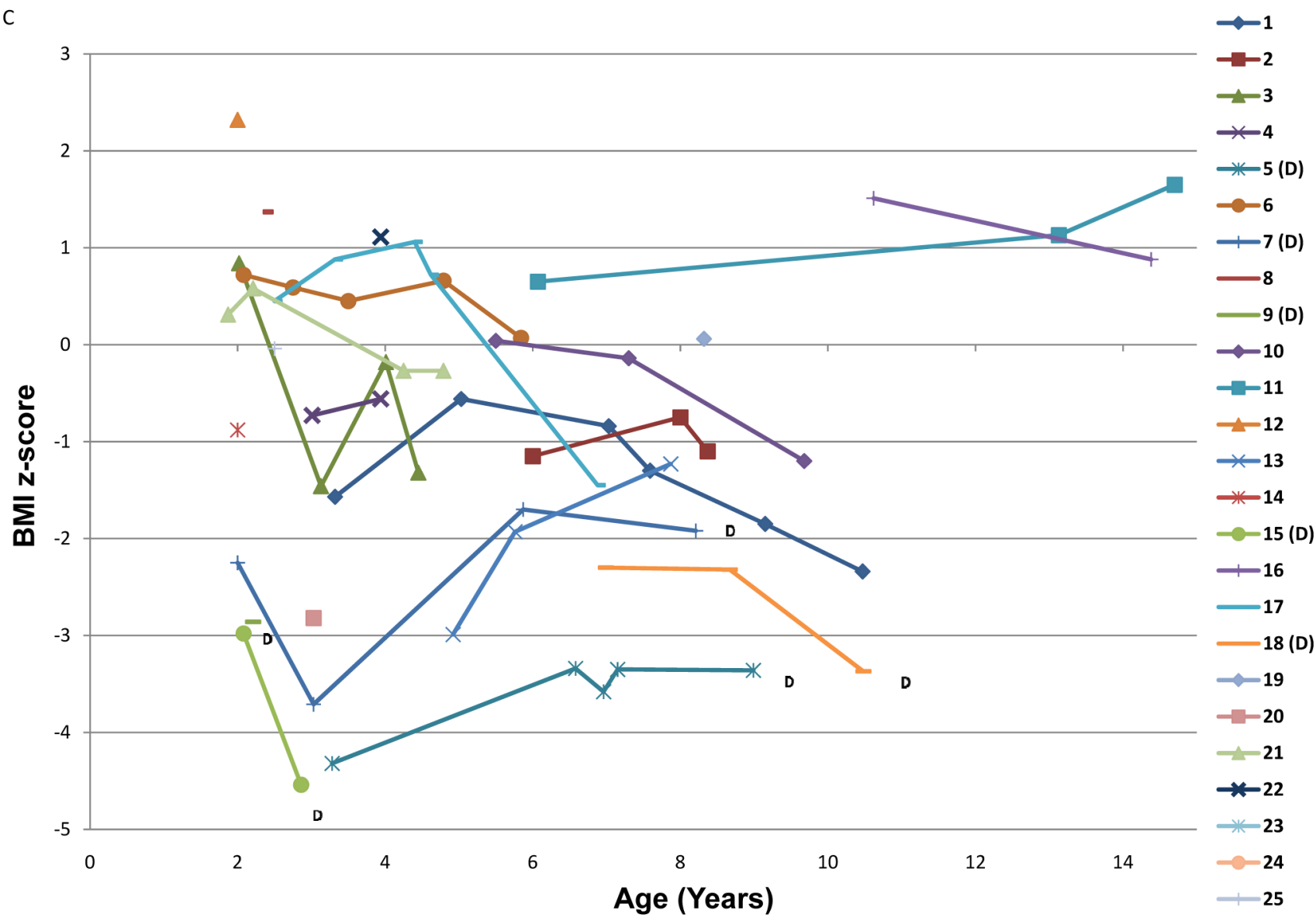

Figure 1. Height-for age, weight-for-age, and BMI z-scores over time for each subject enrolled in the study

Each line represents all available growth data for a unique subject; the numbers in the key correspond to the ID numbers listed in the demographics (Table 1). (D) after a subject's ID number signifies that they are now deceased. A) Height-for-age z-score plotted by subject age in years. B) Weight-for-age z-score plotted by age in years C.) BMI z-score plotted by age in years. 


\begin{tabular}{|c|c|c|c|c|c|c|c|c|c|c|c|c|c|c|c|c|c|c|c|c|c|c|c|c|c|c|c|}
\hline & 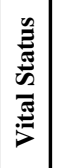 & & 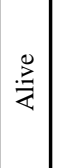 & & $\stackrel{0}{\frac{0}{4}}$ & & 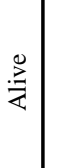 & & 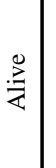 & & 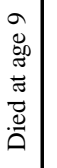 & & 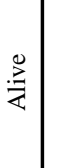 & & 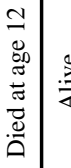 & $\stackrel{\nexists}{\gtrless}$ & & 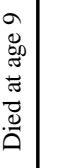 & 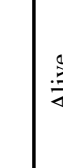 & & 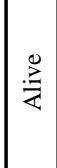 & 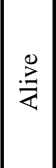 & & 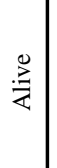 & & 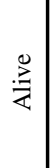 & \\
\hline & 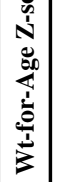 & $\stackrel{\bar{\infty}}{-}$ & $\begin{array}{l}\stackrel{0}{e} \\
\vec{i} \\
i\end{array}$ & $\begin{array}{l}\bar{n} \\
i \\
i\end{array}$ & 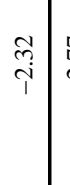 & $\begin{array}{ll}\hat{i} & \\
\text { i } & \end{array}$ & $\frac{O}{r}$ & & $\begin{array}{l} \pm \\
\\
\end{array}$ & $\begin{array}{c}\tilde{\sigma} \\
\hat{i}\end{array}$ & $\begin{array}{c}\overrightarrow{+} \\
\stackrel{+}{+}\end{array}$ & $\underset{\substack{i \\
i}}{i}$ & $\frac{8}{i}$ & $\begin{array}{l}\vec{m} \\
\overrightarrow{1}\end{array}$ & $\begin{array}{l}\hat{0} \\
\dot{1} \\
\end{array}$ & \begin{tabular}{c|c}
$\mathcal{Y}$ \\
$\stackrel{T}{T}$ \\
\end{tabular} & 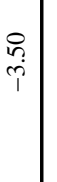 & $\begin{array}{l}8 \\
\dot{T} \\
+\end{array}$ & $\begin{array}{l}0 \\
\stackrel{0}{i}\end{array}$ & 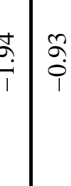 & $\hat{\imath}$ & $\stackrel{\mathscr{f}}{\tilde{i}}$ & $\begin{array}{l}\stackrel{+}{d} \\
\text { în }\end{array}$ & $\begin{array}{l}\hat{i} \\
\mathbf{i}\end{array}$ & $\begin{array}{l}\stackrel{8}{0} \\
\stackrel{1}{*}\end{array}$ & $\begin{array}{l}5 \\
\text { bे } \\
1\end{array}$ & $\begin{array}{l}\text { ț } \\
i \\
i\end{array}$ \\
\hline & 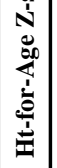 & ণิ & 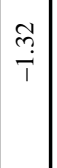 & $\begin{array}{c}\hat{\infty} \\
\stackrel{i}{i}\end{array}$ & $\begin{array}{l}\mathcal{F} \\
i \\
i\end{array}$ & \begin{tabular}{c|c}
$\vec{F}$ & \\
$\dot{1}$ & 9
\end{tabular} & 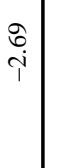 & $\begin{array}{c}\stackrel{a}{\alpha} \\
\stackrel{i}{i}\end{array}$ & $\stackrel{m}{\rightarrow}$ & $\begin{array}{l}\overrightarrow{\bar{b}} \\
\overline{1}\end{array}$ & $\begin{array}{l}\stackrel{0}{a} \\
i \\
i\end{array}$ & $\begin{array}{l}\begin{array}{r}0 \\
i \\
i\end{array} \\
\end{array}$ & 卓 & 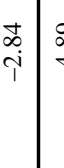 & 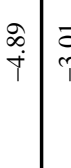 & $\begin{array}{ll}\overrightarrow{0} \\
\vec{i} \\
\vec{i}\end{array}$ & 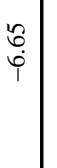 & & $\begin{array}{l}\bar{a} \\
\\
\end{array}$ & 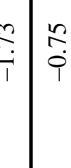 & \begin{tabular}{|l}
$t$ \\
\\
$i$
\end{tabular} & 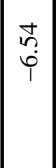 & $\begin{array}{c}\infty \\
\stackrel{\infty}{i} \\
i\end{array}$ & 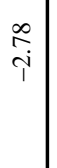 & $\begin{array}{l}\infty \\
\stackrel{\infty}{+} \\
\stackrel{1}{1}\end{array}$ & & $\begin{array}{l}\vec{m} \\
i \\
i\end{array}$ \\
\hline & 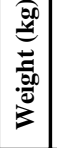 & $\stackrel{\infty}{=}$ & $\begin{array}{l}0 \\
\ddot{i} \\
\vec{i}\end{array}$ & $\stackrel{2}{r}$ & $\overline{9}$ & $\begin{array}{l}\infty \\
\infty \\
\infty\end{array}$ & $\stackrel{\Xi}{\mathrm{I}}$ & & $\stackrel{?}{ \pm}$ & : & $\infty$ & $\stackrel{0}{i}$ & $\underline{n}$ & $\dot{0}$ & $\stackrel{\mathfrak{I}}{ \pm}$ & $\stackrel{\circ}{=}$ & $\stackrel{\circ}{i}$ & 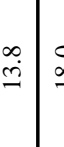 & $\begin{array}{l}0 \\
\infty \\
-\infty\end{array}$ & $\stackrel{m}{c}$ & $\stackrel{\infty}{+}$ & $\stackrel{\curvearrowright}{\infty}$ & $\overrightarrow{\mathrm{I}}$ & $\stackrel{\text { ㄱ. }}{=}$ & $\stackrel{\infty}{+}$ & $\stackrel{\circ}{\stackrel{\leftrightarrow}{g}}$ & $\stackrel{\sim}{\sim}$ \\
\hline & 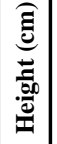 & $\begin{array}{l}\infty \\
\stackrel{\leftrightarrow}{\circ}\end{array}$ & $\frac{n}{m}$ & $\grave{尺}$ & $\begin{array}{l}\stackrel{\infty}{0} \\
\stackrel{\ominus}{=}\end{array}$ & $\stackrel{\leftrightarrow}{\vec{*}}$ & 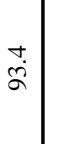 & $\frac{m}{\infty}$ & 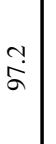 & 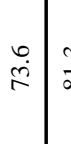 & $\frac{m}{\dot{\infty}}$ & in & $\stackrel{\stackrel{0}{\mathrm{j}}}{\mathrm{g}}$ & $\begin{array}{l}n \\
\infty \\
\infty \\
0\end{array}$ & 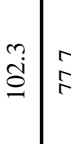 & 尺̊. & $\stackrel{\odot}{\dot{f}}$ & & $\begin{array}{l}\stackrel{0}{\circ} \\
\stackrel{\rho}{=}\end{array}$ & 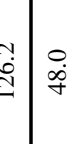 & \begin{tabular}{|l}
$\infty$ \\
$\dot{1}$ \\
$\stackrel{5}{0}$
\end{tabular} & ? & $\stackrel{\circ}{\stackrel{8}{8}}$ & $\stackrel{\Xi}{=}$ & in & & $\begin{array}{l}\infty \\
\stackrel{\infty}{q}\end{array}$ \\
\hline$\dot{\widehat{\overbrace{}}}$ & 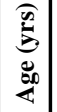 & $m$ & $\stackrel{n}{\varrho}$ & $\stackrel{\simeq}{\simeq}$ & $\underset{\infty}{+}$ & $\begin{array}{lll}0 & 4\end{array}$ & 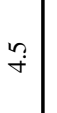 & $\Xi$ & $\vec{m}$ & $\stackrel{m}{m}$ & $\stackrel{\circ}{\circ}$ & $n$ & $\stackrel{\vec{r}}{\dot{r}}$ & $\stackrel{\circ}{-}$ & $\underset{\infty}{\infty}$ & $\stackrel{t}{i}$ & -1 & ?̧: & ? & $\overline{6}: 0$. & 导 & 9 & $\dot{q}$ & $\stackrel{\curvearrowright}{\curvearrowright}$ & $\because$ & $\stackrel{?}{\sim}$ & ת \\
\hline $\begin{array}{l}= \\
\frac{0}{0} \\
\frac{0}{0} \\
0 \\
0\end{array}$ & 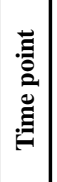 & 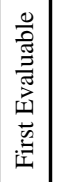 & 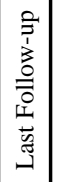 & 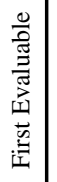 & 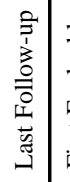 & 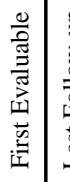 & 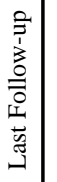 & 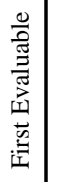 & 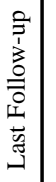 & 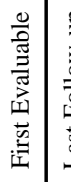 & 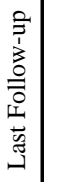 & 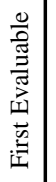 & 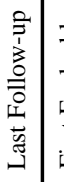 & 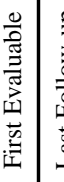 & 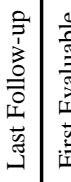 & 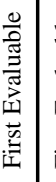 & 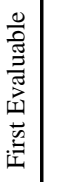 & 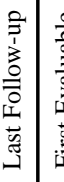 & 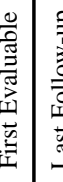 & 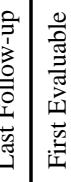 & 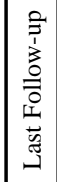 & 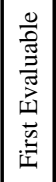 & 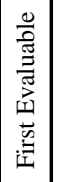 & 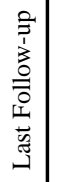 & 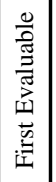 & 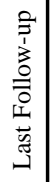 & 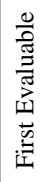 \\
\hline 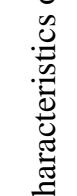 & 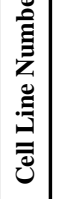 & 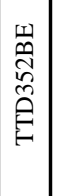 & & 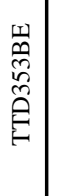 & & 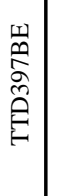 & & 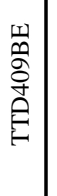 & & 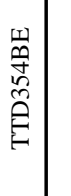 & & 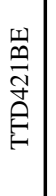 & & 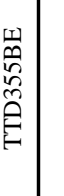 & & 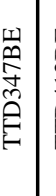 & 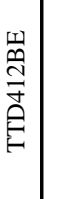 & & 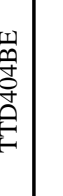 & 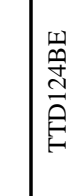 & & 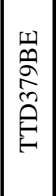 & 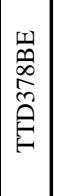 & & 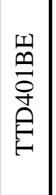 & & 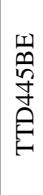 \\
\hline $\begin{array}{l}0 \\
\stackrel{0}{2} \\
0 \\
0\end{array}$ & 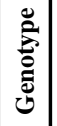 & $\hat{\tilde{x}}$ & & 官 & & 家 & & $\hat{\tilde{x}}$ & & $\hat{\tilde{x}}$ & & 完 & & 完 & & $\begin{array}{l}\frac{5}{5} \\
0 \\
\frac{\tilde{z}}{5} \\
5\end{array}$ & $\hat{\tilde{x}}$ & & 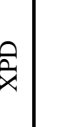 & 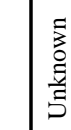 & & 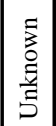 & 完 & & 完 & & $\hat{\frac{\partial}{x}}$ \\
\hline$\vec{G}$ & $\begin{array}{l}\mathscr{\Xi} \\
\approx \\
\approx\end{array}$ & 3 & & 3 & & 3 & & 3 & & 3 & & 3 & & 3 & & 3 & 3 & 3 & 3 & $\frac{7}{3}$ & & $\varangle$ & 3 & & 3 & & 3 \\
\hline 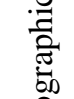 & 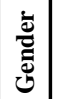 & 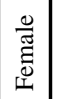 & & 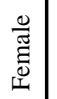 & & $\frac{\frac{0}{2}}{\frac{\pi}{\Sigma}}$ & & $\frac{0}{\frac{\pi}{\Sigma}}$ & & 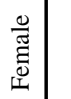 & & 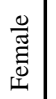 & & $\frac{0}{\pi}$ & & 霙 & $\frac{0}{\sum^{\frac{\pi}{2}}}$ & & $\frac{\frac{0}{5}}{\frac{\pi}{2}}$ & $\frac{\frac{0}{\pi}}{2}$ & & $\frac{0}{\tilde{\sigma}^{2}}$ & $\frac{\frac{0}{\pi}}{\frac{\pi}{2}}$ & & $\frac{0}{\tilde{m}}$ & & $\frac{\varrho}{\frac{\sigma}{\pi}}$ \\
\hline ฮี & I & - & & $\mathrm{N}$ & & $m$ & & 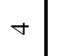 & & in & & 0 & & $r$ & & $\infty$ & $a$ & $s$ & 운 & $=$ & & $\simeq$ & 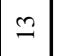 & & \pm & & $\underline{n}$ \\
\hline
\end{tabular}




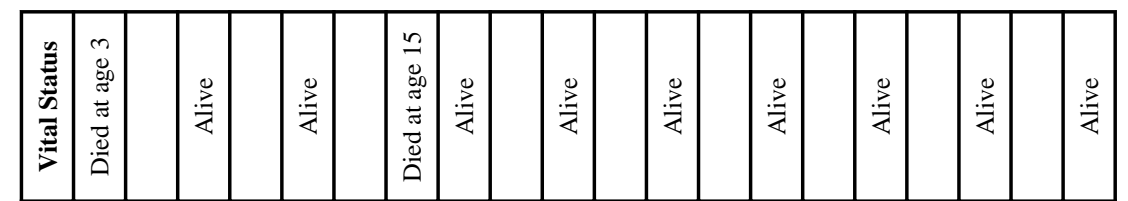
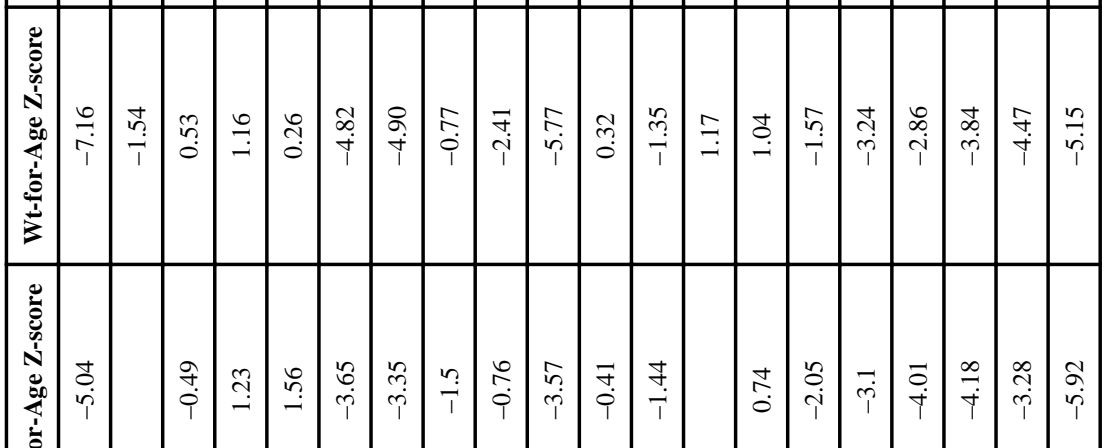

紊

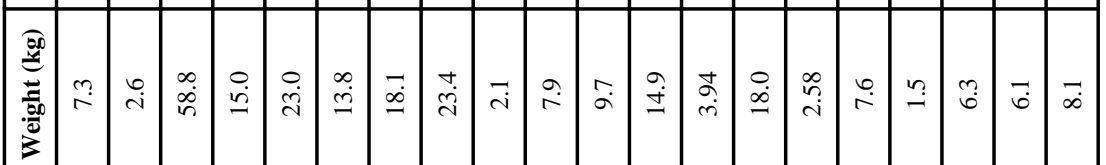

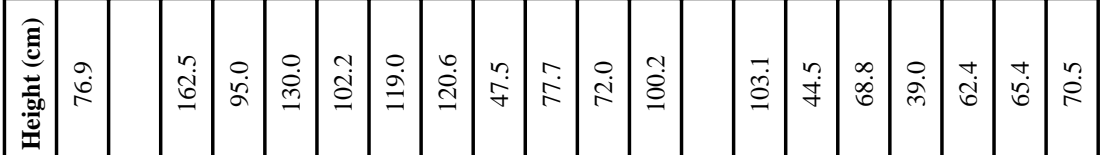

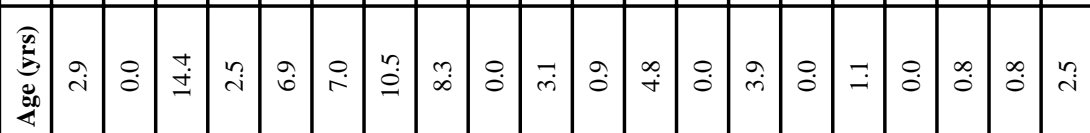

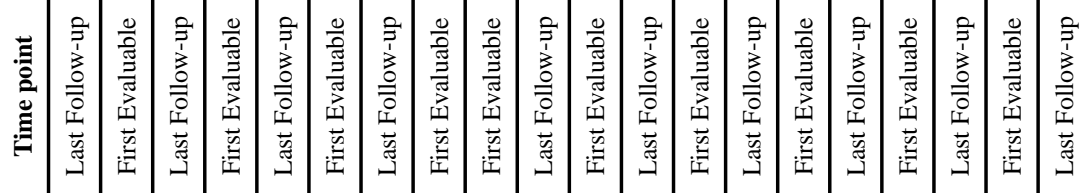

\begin{tabular}{|c|c|c|c|c|c|c|c|c|c|c|}
\hline 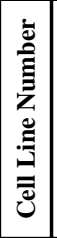 & 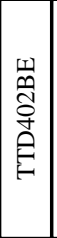 & 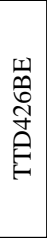 & 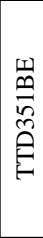 & 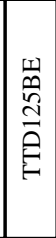 & 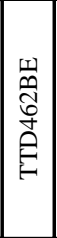 & 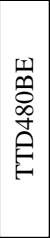 & 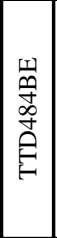 & 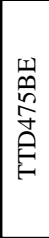 & 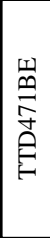 & 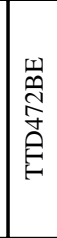 \\
\hline 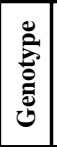 & $\begin{array}{l}\bar{z} \\
\text { E }\end{array}$ & 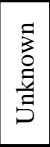 & $\stackrel{\vec{x}}{\hat{x}}$ & $\begin{array}{l}\bar{z} \\
\overline{0} \\
\overline{0} \\
\overline{5}\end{array}$ & $\hat{\bar{x}}$ & $\begin{array}{l}\bar{z} \\
\text { 恶 }\end{array}$ & 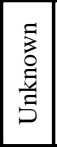 & $\stackrel{\partial}{\vec{x}}$ & 官 & 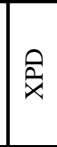 \\
\hline 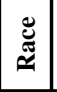 & 3 & $\frac{n}{3}$ & 3 & $\frac{\pi}{3}$ & 3 & 3 & 3 & 3 & 3 & 3 \\
\hline 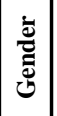 & 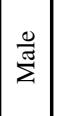 & 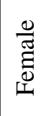 & $\frac{\frac{0}{5}}{\frac{w}{z}}$ & 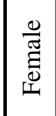 & 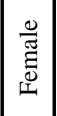 & $\begin{array}{l}\frac{0}{\tilde{w}} \\
\text { 芯 } \\
\text { w }\end{array}$ & 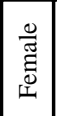 & $\frac{\frac{0}{\pi}}{\frac{\pi}{\Sigma}}$ & $\frac{\frac{0}{5}}{\frac{\sigma}{\Sigma}}$ & $\frac{\frac{0}{\pi}}{\frac{\pi}{\Sigma}}$ \\
\hline 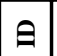 & $\stackrel{ }{2}$ & $=$ & $\stackrel{\infty}{\sim}$ & 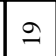 & i & $\bar{\lambda}$ & ה & $\pi$ & $\stackrel{4}{4}$ & तु \\
\hline
\end{tabular}


Table 2

Anthropometric Measurements and Nutritional Laboratory Indices.

\begin{tabular}{|l|c|c|c|}
\hline & Mean Value \pm SD & Normal Range & N \\
\hline Age at Last Visit (years) & $6.4 \pm 3.8$ & N/A & 25 \\
\hline Height-for-age Z-score at First Evaluation & $\mathbf{- 2 . 7 5} \pm \mathbf{2 . 0 9}$ & N/A & 23 \\
\hline Height-for-age Z-score at Last Visit & $\mathbf{- 2 . 9 0 \pm \mathbf { 2 . 4 5 }}$ & N/A & 23 \\
\hline Weight-for-age Z-score at First Evaluation & $\mathbf{- 2 . 6 0 \pm \mathbf { 2 . 3 5 }}$ & N/A & 24 \\
\hline Weight-for-age Z-score at Last Visit & $\mathbf{- 3 . 2 4} \pm \mathbf{3 . 2 9}$ & N/A & 25 \\
\hline Change in Height-for-age Z-score per year & $-0.18 \pm 0.42$ & N/A & 21 \\
\hline Change in Weight-for-age Z-score per year & $-0.36 \pm 0.51$ & N/A & 22 \\
\hline Albumin $(\mathrm{g} / \mathrm{dL})$ & $3.8 \pm 0.3$ & $2.9-4.7$ & 25 \\
\hline Hemoglobin $(\mathrm{g} / \mathrm{dL})$ & $12.5 \pm 0.9$ & $10.1-15.5$ & 24 \\
\hline Hemoglobin A2 (\%) & $\mathbf{4 . 2} \pm \mathbf{1 . 2}$ & $2.2-3.2$ & 19 \\
\hline MCV (fL) & $74 \pm 7$ & $69-99$ & 24 \\
\hline Cholesterol $(\mathrm{mg} / \mathrm{dL})$ & $156 \pm 31$ & $100-200$ & 25 \\
\hline 25 OH Vitamin D (ng/mL) & $35 \pm 12$ & $10-80$ & 25 \\
\hline Vitamin B12 (pg/mL) & $1165 \pm 414$ & $211-1320$ & 20 \\
\hline Serum Iron $(\mu \mathrm{gg} / \mathrm{dL})$ & $72 \pm 26$ & $30-150$ & 20 \\
\hline Transferrin $(\mathrm{mg} / \mathrm{dL})$ & $290 \pm 42$ & $204-345$ & 20 \\
\hline Saturation $(\%)$ & $18 \pm 6$ & $15-62$ & 20 \\
\hline TSH (mcIU/mL) & $3.0 \pm 1.5$ & $0.3-8.6$ & 17 \\
\hline Folate (ng/mL) & $22 \pm 14$ & $3-31$ & 18 \\
\hline
\end{tabular}

All laboratory data represent measurements obtained at baseline assessment and entry into the cohort. 